\title{
Objectless locative prepositions in British English
}

\author{
Richard Stockwell \& Carson T. Schütze ${ }^{*}$
}

\begin{abstract}
In British English, sentences like This film has monsters in are possible without the pronoun it. Descriptively, we refine the landscape of the phenomenon, identifying restrictions on the distribution and interpretation of OLPs, dialectal variation within British English, and an A-bar movement restriction on monsters. Analytically, we argue against an A-movement analysis (Griffiths \& Sailor), and ponder alternatives from a cross-linguistic perspective.
\end{abstract}

Keywords. locative prepositions; silent complements; have/with; British English; R-pronouns; crossing dependencies

\section{Introduction.}

1.1. BASIC FACTS. Whereas most dialects of English (Eng) require the pronoun in (1a) and (2a), British English (BrEng) allows synonymous objectless locative prepositions (OLPs) (1b) and (2b). This phenomenon was first analyzed ${ }^{1}$ by Griffiths \& Sailor (2015a,b, 2017; Sailor \& Griffiths 2017) (G\&S) under the moniker Prepositional Object Gaps (POGs). The pronoun (a) or gap (b) obligatorily corefers with an overt DP. ${ }^{2}$

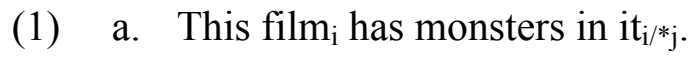

b. This film $\mathrm{i}_{\mathrm{i}}$ has monsters in $\mathrm{i}_{\mathrm{i}} /{ }^{\mathrm{j}} \mathrm{j}$.
Eng

BrEng

Eng

BrEng [1a]

We use the term "Objectless Locative Preposition (OLP) construction" to refer just to cases like (1b) and (2b), which are possible only for British speakers, as distinct from other environments where all Englishes allow a preposition with no overt complement (cf. $\S 3$ below). In both (1a,b) and $(2 \mathrm{a}, \mathrm{b})$ the preposition $(\mathrm{P})(\mathrm{e} . \mathrm{g}$. in) expresses a relation between the Figure (monsters) and the Ground (film). In clausal OLPs (1b), the Ground surfaces as the subject of the clause (3a); in nominal OLPs (2b), the Ground surfaces as the head of the DP (3b); compare the existential (3c).
a. Ground $\mathrm{i}_{\mathrm{i}}$ has Figure [PP $\left.\mathrm{P} \_\mathrm{i}\right]$.
c. There BE Figure [PP P Ground].

b. [DP Ground ${ }_{\mathrm{i}}$ with Figure $\left.\left[\mathrm{PP} \mathrm{P}_{\mathrm{i}} \mathrm{i}\right]\right]$

Notationally, $(4 a, b)$ collapse the synonymous $(1 \mathrm{a}, \mathrm{b}),(2 \mathrm{a}, \mathrm{b})$ into a single line. " $<>$ " surrounds pronouns that are optional only in BrEng, and asserts obligatory coreference between the subject/head and the pronoun. Otherwise "( )" indicates optionality in all Eng.

a. This film has monsters in $<$ it $>$.

b. the film with monsters in $<$ it $>$

\footnotetext{
* Thanks to four anonymous reviewers; audiences at the American Indian Seminar and Syntax Seminar at UCLA, LangUE at Essex, and the LSA; Dylan Bumford, Tim Hunter, Hilda Koopman, Andrew McIntyre, Pam Munro, Neil Myler, Ethan Poole, Dominique Sportiche, and Peter Svenonius. This research was supported by a UCLA Faculty Academic Senate Grant to the second author. All errors are ours. Authors: Richard Stockwell (rstockwell15@ucla.edu) \& Carson T. Schütze (cschutze@ucla.edu), University of California, Los Angeles.

${ }^{1}$ This phenomenon has been observed in the descriptive literature (Swan 1995, Algeo 2006:197) and (foot)noticed by syntacticians (Belvin \& den Dikken 1997:168, fn. 17, McIntyre 2005:5).

${ }^{2}$ Example numbers in [square brackets] refer to G\&S's 2015a paper; in \{curly brackets\} to S\&G's 2017 handout; in \backslashes $\backslash$ to G\&S's 2017 handout.
} 
1.2. THEORETICAL ISSUES. What is the nature of the gap in (1b) and (2b), denoted pretheoretically with an underscore? We demonstrate that the "silencing" of the pronoun is not free: many syntactic manipulations that are possible on (1a) and (2a) turn (1b) and (2b) bad, so OLPs must be different beyond nonpronunciation of the pronoun. And what is it about BrEng that allows such gaps where all other Eng to our knowledge (Canadian, Australian) do not?

1.3. GOALS AND ROADMAP. We refine the descriptive landscape of OLPs $(\$ 2)$ and superficially similar phenomena in Eng ( $(3)$. We then discuss G\&S's analysis and challenges it faces (§4). We consider alternative analyses from a cross-linguistic perspective (§5) before concluding (§6).

\section{The empirical landscape of OLPs.}

2.1. PredicAtes that LicENSE OLPs: haVE, WITH, ... As observed by Swan (1995:433), OLPs depend on the presence of have (1) or with (2). Thus in (5) the existential is bad (a), despite the apparent synonymy of (b) and (c).

(5) a. Don't watch that film $\mathrm{m}_{\mathrm{i}}$-there's a monster in * $\left(\mathrm{it}_{\mathrm{i}}\right)$ !

b. There's a monster in that film. c. That film has a monster in $<i t>$.

Likewise in (6), OLPs with the Saxon genitive (a) and a because-clause (b) are bad for lack of a have/with frame. ${ }^{3}$

(6) a. That file's papers are all in *(it $\left.\mathrm{it}_{\mathrm{i}}\right)$.

b. This film $\mathrm{m}_{\mathrm{i}}$ is frightening because there are so many monsters in *(iti $)$. $\{\mathrm{cf} .2 \mathrm{~b}\}$

Swan (1995:174) observes that have got works like have (7). We add that verbs that can be roughly synonymous with have fail to license OLPs (8).

(7) My socks have got holes in $<$ them $_{\mathrm{i}}>$.

(8) a. This box bhas $/ *$ contains $\}$ papers in $\left\langle\mathrm{it}_{\mathrm{i}}>\right.$.

b. This wallet ${ }_{\mathrm{i}}$ can $\{$ have/*hold $\}$ up to 20 credit cards in $<\mathrm{it}_{\mathrm{i}}>$.

Negation of the licensing predicates is allowed:

(9) a. This film ${ }_{i}\{$ doesn't have/hasn't got $\}$ monsters in $<\mathrm{it}_{\mathrm{i}}>$.

b. The film $m_{i}$ without monsters in $\left\langle\mathrm{it}_{\mathrm{i}}\right\rangle$ was far more enjoyable.

The necessity of a have- or with-frame for OLPs sits nicely with analyses where (at least on some uses) have "contains" with (Tremblay 1996, Schütze 2001, Levinson 2011, i.a.). In fact, McIntyre (2005:5) marshals the parallel behavior of have (1b) and with (2b) with respect to OLPs as evidence for decomposing have as be + with.

Ritter \& Rosen (1997) and Harley (1998) term the use of have in (1a) and (8) "Locational"; similarly, Myler (2016) uses "Locative"; other uses of have do not license OLPs (10), e.g., modal have (got) to (a), experiencer have (b), causative have (c):

(10) a. For a film $\mathrm{m}_{\mathrm{i}}$ to be successful, monsters have (got) to be in *(iti $\mathrm{i}_{\mathrm{i}}$ !

b. The boiler $r_{i}$ had its $s_{i}$ tank collecting water in *(iti $)_{i}$.

c. The film $\mathrm{i}_{\mathrm{i}}$ 's director had there be lots of monsters in * $\left(\mathrm{it}_{\mathrm{i}}\right)$.

Additional licensing verbs are plausibly built from have: need (11), which has been argued to contain possessive have (Harves \& Kayne 2012); and get (12), which has been claimed to be

\footnotetext{
${ }^{3}$ Alternatively, the problem with (6), and for that matter (5a), could be that there is no local c-commanding binder for the gap. The same may be true for $(10 \mathrm{a}, \mathrm{c})$ below.
} 
the inchoative of have (Kimball 1973, Emonds 1994:164, i.a.). ${ }^{4}$ Again, roughly synonymous verbs fail to license OLPs.

(11) This film ${ }_{\mathrm{i}}$ \{needs/??requires/??demands $\}$ more monsters in $<\mathrm{it}_{\mathrm{i}}>$.

(12) Over the past year, the guestbook $\operatorname{lgot}^{*}$ obtained/*acquired $\}$ so many rude entries in $<\mathrm{it}_{\mathrm{i}}>$ that it had to be thrown away.

2.2. RESTRICTIONS ON THE GROUND. As complement of $\mathrm{P}$, it and inanimate them (13) are possible; $1^{\text {st }}$ and $2^{\text {nd }}$ person pronouns are impossible (14); and $3^{\text {rd }}$ person human pronouns call for further investigation - G\&S note the badness of (15a), we note the relative goodness of (15b).

(13) a. These boxes ${ }_{i}$ have papers in $\left\langle\right.$ them $_{i}>$. b. the boxes ${ }_{i}$ with papers in $\left\langle\right.$ them $\left._{i}\right\rangle$

(14) I/You have \{poison/radioactive chemicals\} in *(me/you).

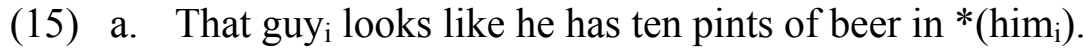

b. ?The poisoned $\mathrm{spy}_{\mathrm{i}}$ with radioactive chemicals in $\left\langle\mathrm{him}_{\mathrm{i}}\right\rangle$ is dying.

2.3. The Figure CAN BE ANY KIND OF DP. In addition to bare plurals (above), all sorts of DPs can appear as the Figure in situ (but cf. $\S 4.3$ for failed attempts to move it):

(16) a. This film $\mathrm{i}_{\mathrm{i}}$ has a monster in $<\mathrm{it}_{\mathrm{i}}>$-namely, Godzilla.

b. At least two dozen films ${ }_{i}$ have Eddie Redmayne in $<$ them $_{i}>$.

c. $\mathrm{It}_{\mathrm{i}}$ has every living member of Monty Python in $<\mathrm{it}_{\mathrm{i}}>$.

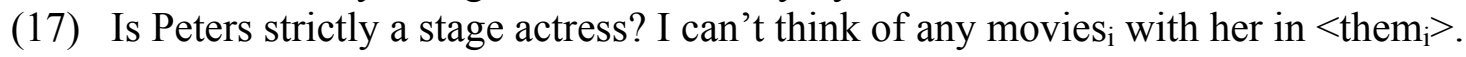

(18) Q: Do you have any pink jellybeans? A: Sure, this jar $\mathrm{r}_{\mathrm{i}}$ has lots/plenty/50 (of them) in $<\mathrm{it}_{\mathrm{i}}>$.

\subsection{CONSTRAINTS ON THE SPATIAL RELATIONS.}

2.4.1. PREPOSITIONS. G\&S claim that many spatial prepositions license OLPs. But this does not hold for RS, for whom OLPs are essentially restricted to in (above) and on (19).
a. This box $\mathrm{x}_{\mathrm{i}}$ has spots on $<\mathrm{it}_{\mathrm{i}}>$.
b. the box $\mathrm{i}_{\mathrm{i}}$ with spots on $<\mathrm{it}_{\mathrm{i}}>$

Specifically, G\&S (2017) claim that OLPs are also licensed by behind, inside, below, above, beyond (projective Ps); around, through, across, along, over, under, past (extended Ps); between (bounded P); up and down (Particles). (The taxonomy is from Svenonius 2010.) Their examples supporting these claims are in (20) (their judgments) ${ }^{5}$ they provide no examples illustrating OLPs with inside, beyond, around, through, over. They further claim that if any $\mathrm{P}$ is modified by a deictic particle (20b) or a projective $\mathrm{P}$ is modified by a measure phrase (20c), OLPs become unavailable.

(20) a. A church ${ }_{\mathrm{i}}$ can usually be found to have a graveyard behind $<\mathrm{it}_{\mathrm{i}}>$.

b. I've just seen a mountain ${ }_{i}$ with some beautiful houses (*down) below $<\mathrm{it}_{\mathrm{i}}>$.

c. Go through the door $\mathrm{i}_{\mathrm{i}}$ with a sign (*a few feet) above $<\mathrm{it}_{\mathrm{i}}>$.

d. This river $\mathrm{i}_{\mathrm{i}}$ has a bridge across $<\mathrm{it}_{\mathrm{i}}>$.

e. Mine's the mug $_{i}$ with the coaster under $<\mathrm{it}_{\mathrm{i}}>$.

f. This street $\mathrm{i}_{\mathrm{i}}$ has an adequate number of streetlights along $\%<\mathrm{it}_{\mathrm{i}}>$.

g. The next bus stop $\mathrm{i}_{\mathrm{i}}$ has a Nando's just past $\%<\mathrm{it}_{\mathrm{i}}>$.

h. Let's sit at those tables $\mathrm{i}_{\mathrm{i}}$ with gaps between $<$ them $_{\mathrm{i}}>$.

i. Stop when you see two houses $\mathrm{i}_{\mathrm{i}}$ with an alleyway between $\%<$ them $_{\mathrm{i}}>$.

\footnotetext{
${ }^{4}$ Sailor \& Griffiths (2017:10) assert that need and get "partially license" OLPs, but do not elaborate.

${ }^{5}$ Further discussion of projective Ps is deferred to $\$ 3.1$, and of $u p$ and down to $\$ 3.2$.
} 
G\&S (2015a:66) assert that four speakers from London and four from other regions fully accepted (20d, e); RS finds them very marginal $\left(?^{*}\right) .{ }^{6}$ And where G\&S report speaker variation (\%) for (20f, g), RS rejects these (*). Cases with between vary: RS considers (20h) "?" while (20i) is "??". For him, (20b) is improved rather than degraded when the deictic particle down is included, and the measure phrase in (20c) is also ameliorating, but possibly for a different interpretation ('above you/one').

2.4.2. SENSES OF IN AND $O N$. The spatial sense of $i n$ was already metaphorically extended in (1) - monsters are not physically located in movies. (21) provides further metaphorical extensions of in to moments (a) and musical contents (b). Temporal senses are also possible (22).

(21) a. Every Hitchcock movie ${ }_{i}$ has truly frightening moments in $<\mathrm{it}_{\mathrm{i}}>$.

b. Hitchcock films $\mathrm{i}_{\mathrm{i}}$ tend to have a lot of suspenseful music in $<$ them $_{\mathrm{i}}>$.

(22) a. The month of May ${ }_{i}$ has two bank holidays in $<\mathrm{it}_{\mathrm{i}}>$.

b. Every term $\mathrm{i}_{\mathrm{i}}$ has at least one manically stressful day in $<\mathrm{it}_{\mathrm{i}}>$.

However, on is difficult to extend metaphorically or temporally, as (23) and (24) show.

(23) a. Tax forms $s_{i}$ have various sources of income and deductions on *(them $\left.{ }_{i}\right)$.

b. a bus $\mathrm{s}_{\mathrm{i}}$ with 50 people on $*\left(\mathrm{it}_{\mathrm{i}}\right)$

(24) Fridays $\mathrm{s}_{\mathrm{i}}$ with faculty meetings on $*\left(\right.$ them $\left._{\mathrm{i}}\right)$ are the worst.

Although S\&G (2017:8) claim that the choice between the structure that licenses an overt it/them and the one that creates an OLP is "evidently without any semantic effects," that is generally not true. Beyond the "extended" uses just examined, for RS (and other SSBE speakers consulted) many straightforwardly spatial examples with on are degraded: compare the good cases in (25) with the degraded ones in (26). One relevant difference seems to be how temporary and/or easily disrupted the relationship is between Figure and Ground, e.g., paint will soon cease to be wet, but butter will remain on (or in) the toast even if it dries; website contents are easily changed, physically glued connections are not, tacking is intermediate. In $(25 \mathrm{e})$, although cars would not be attached to the street, they are effectively unmovable if you do not have the keys. (26c) would be improved if the glasses were glued to the tray, as with a play prop. Some uses seem to depend on quantity modification of the Figure in ways not yet well-understood (27).

(25) a. The $\$ 5$ bill has Jackson's face on $<$ it $>$.

b. I'd like a piece of toast with butter on $<$ it $>$.

c. Now we know it's really Spring: all the trees have (got) leaves on $<$ them $>$ again.

d. All new mattresses must have tags on $<$ them $>$ indicating how they can be cleaned.

e. That street rarely has cars on $<\mathrm{it}>$ - finding parking is easy.

(26) a. A department website typically has faculty and graduate student photos on *(it).

b. The department notice board has grad student photos glued/??tacked on $<$ it $>$.

c. That tray has champagne glasses on ?? $<\mathrm{it}>$.

d. the crate with $\{$ spots/??wet paint $\}$ on $<$ it $>$

(27) a. The High Street has ??(too many) coffee shops on ?<it $>$.

b. Here's a shelf with ??(too many) books on ?<it $>$.

$\backslash c f .21 b \backslash$

Likewise, not all spatial examples with in work so well (28): unlike the sugar, the fly is not (supposed to be) part of the drink (a); (b) may be degraded because it describes a temporary state;

\footnotetext{
${ }^{6}$ RS considers himself a Standard Southern British English (SSBE) speaker.
} 
and the Ground in (c) does not provide a bounded container. ${ }^{7}$

(28) a. a drink with \{sugar/??a fly $\}$ in $<$ it $>$

b. After the storm, the street had six inches of water in $?^{*}<\mathrm{it}>$.

c. The sky has clouds in $*<\mathrm{it}>$.

2.4.3. EXCLUSION OF 'CONSISTS OF' READINGS. OLPs are degraded when the Figures "exhaust" or fully make up the Ground (29), as opposed to characterizing a subset/subpart of it (30). The entire PP is optional in these examples.

(29) a. This house has 12 rooms in *(it).

b. 2020 will be the next year with 366 days in *(it).

c. an album/record/CD with 12 songs on *(it)

d. a book with 22 chapters in *(it)

(30) a. This house has two bathrooms in $<$ it $>$.

b. 2020 will be the next year with an extra day in $<$ it $>$.

c. an album/record/CD with $\{$ a couple of/no $\}$ decent songs on $<\mathrm{it}>$

d. a novel with only one really exciting chapter in $<$ it $>$

3. Superficially similar phenomena in English. We generally agree with G\&S that OLPs cannot be an extension of other situations where the complement to P can be silent in English, chiefly because omission in these cases is not restricted to have/with-frames or to BrEng.

3.1. Prepositions without overt Ground. Svenonius (2010) notes that projective Ps allow anaphoric identification of the Ground quite generally (31). By contrast, he claims that bounded Ps all disallow this, as in (32) (his judgments; many other examples in $\S 3$ are (based on) his):

(31) a. There was a box on the table. Inside ((of) it) was fine Swiss chocolate.

b. There was a beach. Above (it) the cliffs swarmed with birds.

(32) a. There were two stacks of boxes in the warehouse. Between *(them) was a forklift.

b. I saw a small house. Beside *(it) was a gas pump.

However, there seems to be interspeaker variation for some bounded Ps in this regard: examples with between and beside are well attested ${ }^{9}$ and are accepted by CTS, but not RS. Svenonius further claims that allowing a silent Ground correlates with the ability to be followed by there (his judgments), again contrasting projectives with bounded Ps:

(33) a. Get behind/inside/?above/?below/?beyond there.

b. ${ }^{*}$ Get $\{$ between/among/beside/next to $\}$ there.

\footnotetext{
${ }^{7}$ Svenonius (2010:140) suggests that when the particle in has a stative containment reading, it realizes a high head $p$, distinct from the head(s) expressed by prepositions like behind, and likewise for on with the basic meaning of contact. Also distinct is the head that hosts these particles when they are directional, cf. $\$ 3.2$, which he labels Dir.

${ }^{8}$ In this respect they fall in line with exceptions noted by Belvin (1996) to the general pattern whereby alienable "possession" between inanimates requires the PP (ia) — an instance of the "Link Requirement" of Belvin \& den Dikken (1997: (30))—while inalienable possession does not (ib). He provides the counterexamples in (ii) (where OLPs are also possible), where he notes that the Figure is crucial to the normal functioning of the Ground.

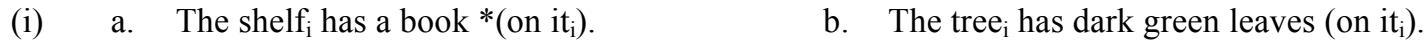

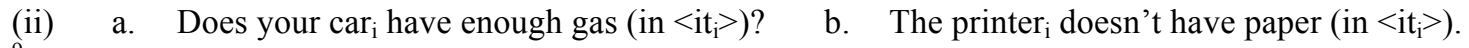

9 "The two armies occupied two hills and between stood a plain of green and gold, rich farmland. (https://www.improfanfic.com/got/segs/got013.txt); “... the airplane began to move without the pilot being able to stop it and another aircraft parked beside was hit.” (https:/www.aibn.no/Aviation/Published-reports/2015-15)
} 
This diagnostic corroborates the interspeaker variation: CTS accepts between and beside in (33b), but RS does not. Recall G\&S claim that between is the only bounded P that licenses OLPs. In light of these observations, verifying their claim requires checking that a speaker who can use between in an OLP cannot drop its complement in any other circumstances. To the extent that between shares nonprototypical behavior with beside, it also seems worth looking more carefully for speakers who might allow OLPs with the latter.

Returning to (31), recall that G\&S claim most projective Ps license OLPs. But given that all English speakers allow such Ps to take a silent Ground, how can we tell? The alleged badness of measure expressions and deictics in projective OLPs $(20 \mathrm{~b}, \mathrm{c})$ might have suggested that Ground omission arises differently there, since those modifiers do not block Ground omission in nonOLPs (34). However, for speakers like RS that do not show the alleged restrictions, there is no way to be certain.

(34) We came to a door. A few feet above (it), a sign swung in the wind.

A third subclass, extended Ps, are claimed to allow a null Ground freely only in their directional use (35); in their locative use (36), a null Ground is possible only with an overt measure expression. Svenonius provides no examples illustrating these claims, but they seem correct:

(35) a. Although our truck exceeded the bridge's weight limit, we drove across (it) safely.

b. The town was almost deserted as we drove through \%(it).

a. I just checked the bridge with the traffic jam again: that oversized truck is not yet *(halfway) across (it).

b. The tunnel is just one lane wide, but there is a short stretch of shoulder *(halfway) through (it).

The methodological consequence is that purported OLPs with extended Ps should not include measure expressions, since these license Ground omission independently. ${ }^{10}$

3.2. Particles without overt Ground. Particles readily appear with no following DP. However, they must then be interpreted as directionals (37), not locatives (38). ${ }^{11}$
a. They fell in (the hole).
b. They slid down (the drainpipe).
c. They jumped on (the back).
d. They climbed up (the wall).

(38) a. Smell the well. There must be a dead opossum in/down *(it).

b. Look at that wobbly ladder. No child should be on/up *(it).

However, adding a measure expression to a particle allows it to express location without a following DP, just as with extended Ps:

(39) a. They had been climbing the tower for 20 minutes but were still only halfway up (it).

\footnotetext{
${ }^{10}$ There is a complication regarding the extended P around, which G\&S claim licenses OLPs. It is lexically ambiguous (Quirk et al. 1985:681), and on the reading 'scattered nearby' it generally allows Ground omission:

(i) There are children around.

On the reading 'encircling' it behaves as in (35) and (36). Thus, genuine OLP examples would have to allow the latter reading without benefit of a measure expression, e.g., (ii), which RS rejects.

(ii) a castle with a moat around $<$ it $>$

${ }^{11}$ Particles without a following overt DP can additionally have idiosyncratic stative meanings, sometimes as a function of the (in)animacy of the subject, where the implicit complement may be obscure or nonexistent.

(i) a. The doctor is in (his office). [ $\neq$ in the pool/kitchen]

b. We're on $(*$ DP $)$. $[=$ about to perform,$\neq$ on a boat $] \quad$ c. $\quad$ The party's on. $[=$ confirmed $]$
} 
b. Once you identify the drain pipe, the blockage should be about three feet down (it).

c. Look at that garage. An SUV is stuck partway in (it).

d. You can't move the truck yet. The palettes are only halfway on (it).

Thus, to establish which particles license OLPs one must test examples that do not contain measure expressions, and the in and on examples in $\$ 2$ did not. G\&S (2017) do the opposite with up and down, yet they conclude that these license OLPs. In fact, the necessity of the measure phrases in (40) makes them like (39), such that it is optional for CTS as well as RS.

(40) a. This rigging has a pirate ??(halfway) up (it).

b. This drainpipe has a blockage ??(a few inches) down (it).

$\backslash c f .8 b \backslash$

For completeness, we note that the quantity expressions observed to ameliorate some OLPs with on in (27) have no such effect on examples like (38b) in (41):

(41) Look at that wobbly ladder. If too many children are/were on *(it), it would fall over.

3.3. PREDICATES OF 'WEARING'. Unlike with OLPs, there is no have/with requirement on omitting the complement of these Ps, and presence/absence of the coindexed pronoun changes the meaning. Furthermore, the subject is human, which is scarcely possible with OLPs (cf. §2.2).
a. John had a hat on.
b. John $n_{\mathrm{i}}$ had a hat on $\underline{\operatorname{him}}_{\mathrm{i}} . \neq(\mathrm{a})$
[he's wearing it]
(cf. put on, take off)
[not wearing it but "with him," e.g., in his pocket]

4. G\&S's analysis: A-movement of the Ground. G\&S propose that OLPs are derived by Amovement of the Ground from the complement of P (43) (as diagrammed in G\&S 2017).

(43) a.

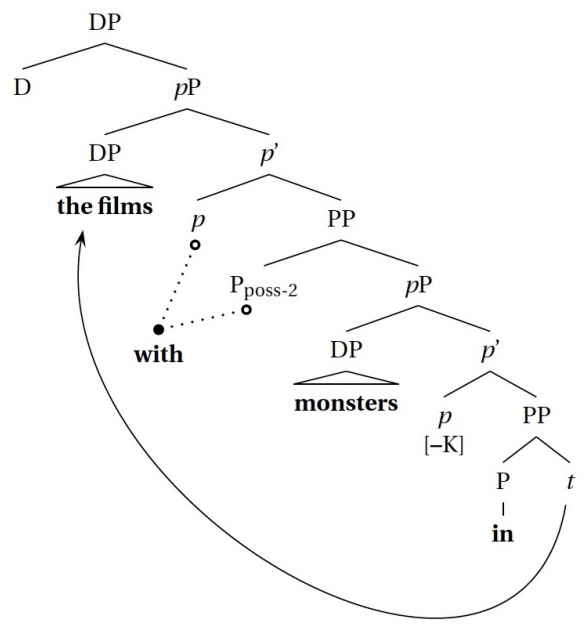

b.

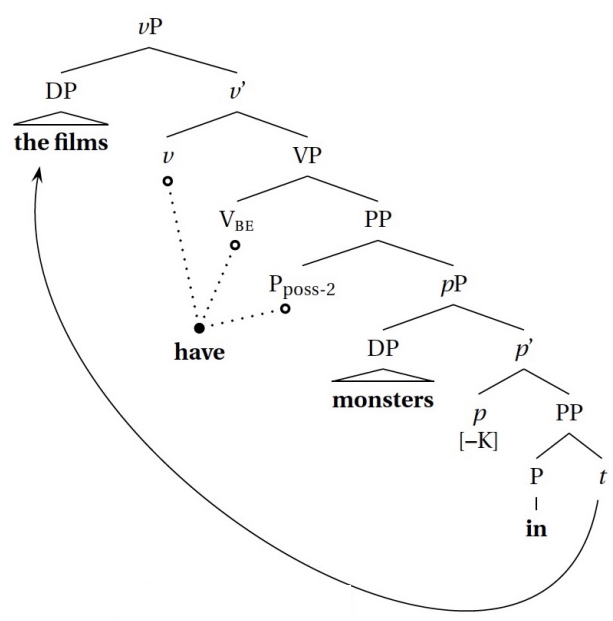

G\&S propose the following parametric distinction: BrEng is different from other Eng in that certain Ps optionally do not assign Case. More precisely, $\mathrm{P}_{\text {poss }}$ (inspired by Levinson 2011), which is the semantic heart of have and with, can select for $p$ Ps whose head is $[ \pm \mathrm{K}] . p[+\mathrm{K}]$ licenses Case on the complement of the $\mathrm{P}$ immediately below it. By contrast, when $p[-\mathrm{K}]$ is deployed, the complement of the P below it must move for Case. S\&G (2017) are explicit that the movements shown in (43) are not themselves movements to Case positions. In (43b), the Ground will subsequently raise to Spec-TP for Case; presumably the movement shown is what allows it to escape the $v \mathrm{P}$ phase. What they have in mind for (43a) is less clear: they state that a "higher, external 
Case assigner" is omitted from the diagram, but any such element would presumably license Case on the entire DP shown, which is distinct from the Ground DP seen moving to Spec- $p$ P.

\subsection{Challenges For A-MOVEMENT.}

4.1.1. SUBEXTRACTION AS SUPPORTING EVIDENCE? G\&S provide (44) as evidence for the crucial step of A-movement in (43), showing what they characterize as a derived island/Freezing effect (Wexler \& Culicover 1980, Corver 2017):

(44) Which president $\mathrm{j}_{\mathrm{j}}$ did you read [a book about $\left.t_{\mathrm{j}}\right]_{\mathrm{i}}$ with a bunch of torn pages in $\left\{\mathrm{it}_{\mathrm{i}} / t_{\mathrm{i}}\right\}$ ? $\{13\}$

With the overt pronoun, the Ground [a book about ...] merges where we see it, and the whphrase which president is free to move out. Without the pronoun, however, the Ground has Amoved from the complement of $i n$, rendering it a derived island and barring sub-extraction of the wh-phrase.

However, as $S \& G$ (2017, note 8) observe, the degree of contrast in (44) shows interspeaker variation. Further, the hypothesized configuration of movements in (44) is good in (45), where the bracketed DP A-moves for Case by passive and/or raising-to-object, but is not rendered a derived island for wh-movement (cf. Bošković 1992):

(45) a. Which celebrity do you believe [a picture of $\left.t_{\mathrm{j}}\right]_{\mathrm{i}}$ to have been stepped on $t_{\mathrm{i}}$ ?

b. Which president $t_{\mathrm{j}}$ does John consider [books by $\left.t_{\mathrm{j}}\right]_{\mathrm{i}}$ to have been plagiarized $t_{\mathrm{i}}$ ?

G\&S give examples only for nominal OLPs (41), but their logic should apply equally well to clausal OLPs. Extraction from the Ground would independently be expected to be bad when it surfaces as the subject of a finite clause (as a Subject Condition violation); but since OLPs can be embedded as nonfinite clauses, we can construct (46) by analogy to (41). (46) shows no contrast as a function of overtness of the pronoun (and minimal degradation). ${ }^{12}$

(46) Which director ${ }_{j}$ do you find [films by $t_{j}$ ] to have too much nudity in $\left\langle\right.$ them $\mathrm{i}_{\mathrm{i}}>$ ?

4.1.2. VARIABLE BINDING INCORRECTLY PREDICTED. If the Ground moves from the complement of $\mathrm{P}$ position, and the Figure c-commands this position as diagrammed in (43b), then the Figure should be able to bind a variable in the Ground. (47a) shows canonical variable binding under ccommand. (47b) and (47c) show that A- and A-bar-movement respectively can reconstruct to allow variable binding. But the bound variable reading of his is not available in the OLP (47d), which it ought to be if the subject had moved (A- or A-bar-wise) from the underscored position; rather, it is interpretively the same as its counterpart with an overt pronoun (47e).

(47) a. Every director ${ }_{i}$ is in a film about his $s_{i}$ youth.

b. [His first film $]_{\mathrm{k}}$ seems to every director $\mathrm{i}_{\mathrm{i}}$ to be $t_{\mathrm{k}}$ immature.

c. [Which film of his $]_{\mathrm{k}}$ does every director ${ }_{\mathrm{i}}$ find $t_{\mathrm{k}}$ immature?

d. [Films about his $\mathrm{j}_{\mathrm{j}} *_{\mathrm{i}}$ youth $]_{\mathrm{k}}$ have every director ${ }_{\mathrm{i}}$ in $\ldots \mathrm{k}$.

e. [Films about his $\mathrm{j}_{\mathrm{j} / *_{\mathrm{i}}}$ youth $]_{\mathrm{k}}$ have every director $\mathrm{i}_{\mathrm{i}}$ in them $\mathrm{k}_{\mathrm{k}}$.

4.1.3. ANAPHOR BINDING INCORRECTLY PREDICTED. Whereas Condition A should be satisfiable prior to (A or A-bar) movement, it is not satisfied in the proposed pre-movement position of OLPs: (48b) and (49b) should be able to mean what their (a) counterparts mean (something trivi$\mathrm{al}$, in the case of (48)), but instead are as bad as their (c) counterparts with overt pronouns.

\footnotetext{
${ }^{12}$ Moreover, the very existence of Freezing as a grammatical constraint has been challenged (see Corver 2017, note 14 for references regarding Spec-TP).
} 
(48) a. Of course $[\text { my car }]_{i}$ is in the picture of itself $f_{i}$.

b. *Of course [the picture of itself $\left.\mathrm{f}_{\mathrm{i}}\right]_{\mathrm{j}}$ has $[\mathrm{my} \text { car }]_{\mathrm{i}}$ in

c. * Of course $\left[\text { the picture of itself } \mathrm{f}_{\mathrm{i}}\right]_{\mathrm{j}}$ has $[\mathrm{my} \text { car }]_{\mathrm{i}}$ in $\mathrm{it}_{\mathrm{j}}$.

(49) a. [John and Mary $]_{i}$ are in my pictures of [each other $]_{i}$ 's birthday parties.

b. *[My pictures of [each other $]_{\mathrm{i}}$ 's birthday parties $]_{\mathrm{j}}$ have $[\text { John and Mary }]_{\mathrm{i}}$ in

c. *[My pictures of [each other $]_{i}$ 's birthday parties $]_{j}$ have $[\text { John and Mary }]_{i}$ in them ${ }_{j}$.

4.1.4. THE STRUCTURE FOR NOMINAL OLPS. While the movement for clausal OLPs (to subject position) is familiar, the creation of the nominal OLP structure resulting from movement is not. On traditional assumptions, if the DP a film raises, then the with-PP which used to contain it would somehow have to become an adjunct to the N(P) film inside the DP that raised (50).

[with [[monsters] [in [DP a film]]] $\rightarrow$ [DP a [NP [NP film] [with [[monsters] $\left[\right.$ in $\left.\left.\left.\left.\left.t_{\mathrm{i}}\right]\right]\right]\right]\right]_{\mathrm{i}}$

Instead, (43a) shows a structure where a film is embedded inside a $p \mathrm{P}$ complement to a higher DP with a silent determiner; it is not clear why that containing DP should behave syntactically or semantically as if its structure were [DP [D a][NP film...]]. Furthermore, choosing the $[+\mathrm{K}]$ alternative in (43a) should yield unattested DPs of the form [DP $\varnothing_{\mathrm{D}}$ with monsters in the film]; S\&G (2017) show the $[+\mathrm{K}]$ alternative yielding the non-OLP the films with monsters in them, but say nothing about why Spec- $p$ P should need to be filled by a base-generated DP just when the lower $p[+\mathrm{K}]$ assigns Case to the pronoun, but is fillable by movement otherwise.

An additional potential problem arises in (51), where the with-phrase appears to the right of a VP adverb: this could involve extraposition of $p^{\prime}$ according to the structure in (43a).

(51) I like how they served [the soup _ $\mathrm{i}$ ] yesterday [with cream in $<\mathrm{it}>]_{\mathrm{i}}$.

4.2. FACTS CONSISTENT With BUT NOT COMPELLING A-MOVEMENT. As G\&S note, with Amovement the following are expected: the A-moved subject of have can raise further (52a) and can create new binding opportunities (52b).

(52) a. This box i $_{\mathrm{i}}$ seems (to appear (to be likely)) to $t_{\mathrm{i}}$ have a skunk in _ _ $\mathrm{i}$.

b. These films $s_{i}$ have each other ${ }_{i}$ 's directors in _

However, both of these observations are equally consistent with base-generating the Ground as the subject of have, as in the grammatical counterparts with an overt pronoun.

\subsection{A-BAR MOVEMENT OF THE FIgURE IS NOT POSSIBLE.}

4.3.1. NEW OBSERVATIONS. In clausal OLP constructions, the Figure cannot undergo A-bar movement, whether by question formation (53) (including D-linking), topicalization (54), it- or pseudo-clefting (55), restrictive or non-restrictive relativization (56), or Heavy NP-Shift (57); all of these are possible when the pronoun is pronounced: ${ }^{13}$

(53) a. What $\mathrm{j}_{\mathrm{j}}$ does this film $\mathrm{i}_{\mathrm{i}}$ have $t_{\mathrm{j}}$ in $\left\{\mathrm{it}_{\mathrm{i}} / *^{*}{ }_{\mathrm{i}}\right\}$ ?

b. [How many monsters $]_{\mathrm{j}}$ does this film $\mathrm{i}_{\mathrm{i}}$ have $t_{\mathrm{j}}$ in $\left\{\mathrm{it}_{\mathrm{i}} / *_{\mathrm{i}}\right\}$ ?

c. [Which of these two actors $]_{\mathrm{j}}$ does this film $\mathrm{i}_{\mathrm{i}}$ have $t_{\mathrm{j}}$ in $\left\{\mathrm{it}_{\mathrm{i}} /{ }^{*}{ }_{\mathrm{i}}\right\}$ ?

(54) Monsters $\mathrm{j}_{\mathrm{j}}$, this film $\mathrm{i}_{\mathrm{i}}$ certainly has $t_{\mathrm{j}}$ in $\left\{\mathrm{it}_{\mathrm{i}} / *^{*} \mathrm{i}_{\mathrm{i}}\right\}$.

(55) a. It's monsters $\mathrm{j}_{\mathrm{j}}$ that this film $\mathrm{i}_{\mathrm{i}}$ has $t_{\mathrm{j}}$ in $\left\{\mathrm{it}_{\mathrm{i}} /{ }^{*}{ }_{\mathrm{i}}\right\}$.

b. What $\mathrm{j}_{\mathrm{j}}$ this film $\mathrm{i}_{\mathrm{i}}$ has $t_{\mathrm{j}}$ in $\left\{\mathrm{it}_{\mathrm{i}} / *_{\mathrm{i}}\right\}$ is a huge monster.

${ }^{13}$ There is no hope of conducting these tests on nominal OLPs: an adjunct island effect is inevitable.

(i) $\quad *[\text { What (kinds of monsters) }]_{\mathrm{j}}$ do you like films $\mathrm{i}_{\mathrm{i}}$ with $t_{\mathrm{j}}$ in $\left(\right.$ them $\left.\mathrm{m}_{\mathrm{i}}\right)$ ? 
(56) a. John likes the monsters $\left[\mathrm{OP}_{\mathrm{j}}\right.$ that the film $\mathrm{m}_{\mathrm{i}}$ has $t_{\mathrm{j}}$ in $\left.\left\{\mathrm{it}_{\mathrm{i}} /{ }^{*}{ }_{\mathrm{i}}\right\}\right]$.

b. Those monsters, which $h_{\mathrm{j}}$ the film $\mathrm{m}_{\mathrm{i}}$ has $t_{\mathrm{j}}$ in $\left\{\mathrm{it}_{\mathrm{i}} / *^{*}{ }_{\mathrm{i}}\right\}$, are very scary.

(57) This film $\mathrm{i}_{\mathrm{i}}$ has $t_{\mathrm{j}}$ in $\left\{\mathrm{it}_{\mathrm{i}} /{ }^{*}{ }_{\mathrm{i}}\right\}$ [some monsters that no one has ever heard of $]_{\mathrm{j}}$.

However, it is not true that the whole OLP structure or even the Figure is entirely "frozen": the subject can be extracted (58a); in contrast to (57), the Figure can be subextracted (extraposed) from (58b); cf. (51). Moreover, wh-in-situ counterparts to (53) are fine (58c).

(58) a. Which film $\mathrm{i}_{\mathrm{i}}$ (do you think) $t_{\mathrm{i}}$ has monsters in $\left\{\mathrm{it}_{\mathrm{i}} /{ }_{\mathrm{i}}\right\}$ ?

b. This box $\mathrm{i}_{\mathrm{i}}$ has [some papers $t_{\mathrm{j}}$ ] in $\left\{\mathrm{it}_{\mathrm{i}} / \mathrm{i}_{\mathrm{i}}\right\}$ [that need to be kept for at least five years]

c. I forget which film $\mathrm{m}_{\mathrm{i}}$ had which British actress in $\left\langle\mathrm{it}_{\mathrm{i}}\right\rangle$.

Emphasizing the claims of §3, the Figure Extraction Restriction shown in (53)-(57) contrasts with what is found for other instances where understood complements of $\mathrm{P}$ are silent (59):

(59) a. What does this box have $t_{\mathrm{j}}$ inside?

b. How many benches $\mathrm{j}_{\mathrm{j}}$ does the liquor store have $t_{\mathrm{j}}$ opposite?

c. What kind of cherry $y_{\mathrm{j}}$ does this sundae have $t_{\mathrm{j}}$ on top?

d. What kind of hat $t_{\mathrm{j}}$ does Mary have $t_{\mathrm{j}}$ on?

In pondering the source of the Figure Extraction Restriction, it is worth noting that OLPs are fully acceptable in types of clauses that may not be as rich in functional structure, including ones that resist overt material (e.g., topicalized DPs) in the left periphery:

(60) a. [That the box had papers in $<i t>$ ] surprised the clerk.

b. [For the box to have papers in $<i t>$ ] would be surprising.

c. ?The magician made [the hat suddenly have a rabbit in $<\mathrm{it}>$ ].

d. That producer never lets [his movies have any nudity in $<$ them $>$ ].

e. Despite [having lots of monsters in $<$ it $>$ ], the film did not appeal to young boys.

f. What?! [A British coin not have the Queen's face on $<\mathrm{it}>$ ]?! Preposterous!

4.3.2. Could this Restriction Follow From movement of the Ground? Perhaps, but only if the Ground first underwent A-bar movement to a position below where it surfaces. A-bar movement of the Ground would create two crossing A-bar chains:

(61) $[\text { which monsters }]_{\mathrm{j}} \ldots$ [[this film $]_{\mathrm{i}}\left[t_{\mathrm{j}}\right.$ in $\left.\left.t_{\mathrm{i}}\right]\right]$ ?

Crossing, in contrast to nested, A-bar chains appear to yield ungrammaticality in a range of structures, e.g. infinitival wh-clauses (62) (Pesetsky 1982, esp. 267ff.)

(62) a. * $*$ Which sonata $]_{\mathrm{i}}$ is [this violin $]_{\mathrm{i}}$ easy $\left[\mathrm{OP}_{\mathrm{j}} \mathrm{PRO}\right.$ to play $t_{\mathrm{i}}$ on $\left.t_{\mathrm{i}}\right]$ ?

b. [Which violin $]_{\mathrm{j}}$ is [this sonata $]_{\mathrm{i}}$ easy $\left[\mathrm{OP}_{\mathrm{i}}\right.$ PRO to play $t_{\mathrm{i}}$ on $\left.t_{\mathrm{j}}\right] ?^{14}$

From (61), the surface order could be derived by further A-movement of this film (if Improper Movement is irrelevant) (63a), or it could be that what undergoes the short A-bar movement is a null operator bound by this film (63b).

(63) a. * * Which monsters $]_{\mathrm{j}}$ does $[\text { this film }]_{\mathrm{i}}$ have $\left[t_{\mathrm{i}}\left[t_{\mathrm{j}}\right.\right.$ in $\left.\left.t_{\mathrm{i}}\right]\right]$ ?

b. $*[\text { Which monsters }]_{\mathrm{j}}$ does [this film $]_{\mathrm{i}}$ have $\left[\mathrm{OP}_{\mathrm{i}}\left[t_{\mathrm{j}}\right.\right.$ in $\left.\left.t_{\mathrm{i}}\right]\right]$ ?

The first little step of A-bar movement might be required if the small clause is a Phase, but it is

\footnotetext{
${ }^{14}$ Contra Chomsky (1977), the goodness of this example is not due to the on-PP being in some surprisingly high position: put $X$ on $Y$ behaves exactly the same.
} 
hard to see what independent evidence one could seek for it. There is, however, evidence that any A-bar movement of the Ground has to be to a position below where it surfaces. What will not work is to A-bar move [this film] directly from complement of P to subject position-G\&S argue against such A-bar movement, i.a. because parasitic gaps ( $p g$ ) are not licensed in adjuncts to have's VP. ${ }^{15}$ Whereas A-bar movement licenses the parasitic gap in (64a), an OLP in the same configuration does not in $(64 \mathrm{~b}):^{16}$

(64) a. Which cups $s_{\mathrm{i}}$ did they drink coffee from $t_{\mathrm{i}}$ [without anyone washing $p g_{\mathrm{i}}$ afterwards]?

b. *These cups ${ }_{i}$ have had coffee in __ ${ }_{i}$ [without anyone washing $p g_{\mathrm{i}}$ afterwards].

Likewise, if the Ground simply undergoes A-movement as diagrammed in (43b) above, the restrictions observed in $\$ 4.4 .1$ would not be expected, since crossing of an A-chain and an A-bar chain is not excluded (65):

(65) Who(m) $)_{\mathrm{i}}$ does $\mathrm{John}_{\mathrm{j}}$ strike $t_{\mathrm{i}}$ as (being) $t_{\mathrm{j}}$ selfish?

4.4. Awaiting EXPLANATION. Among the further empirical properties of OLPs observed by G\&S, two do not seem to follow immediately from the A-movement account: the restriction of licensing to have/with, (which is stipulated as a unique property of $\mathrm{P}_{\text {poss }}$ ) and the (near?) ban on human/animate Grounds. Likewise, the restrictions we observed in $\$ 2.4$ on the uses of in/on (and for some speakers the restriction to those two prepositions) also do not seem obviously derivable from A-movement.

5. In search of alternatives. To the extent that both A- and A-bar-movement directly relating the Ground to the OLP gap seem to derive incorrect predictions and fail to derive attested restrictions, alternatives should be explored.

5.1. WhAt OTHER ANALYSES ARE AVAILABLE FOR THE OLP GAP IN PRINCIPLE? One possibility is that the gap in OLPs might be an in situ silent element, call it pro; such has been posited in complement positions for recipe/instructional English (see Stowell \& Massam 2017 for review). This pro would have to be obligatorily (and perhaps locally) bound (as noted by S\&G (2017:5)), but perhaps that requirement can be enforced by whatever mechanism forces the corresponding overt pronoun to be so bound (the Link Requirement). Another possibility is that the gap might reflect absence of any syntactically projected position whatsoever (as might be argued for some of the cases in §3); we would then need the Link Requirement to be enforceable purely semantically.

The challenge for pursuing either possibility is that it seems hard to derive from them any predictions about constraints on OLPs from independent facts about English. In such circumstances, we suggest looking to other languages for inspiration; and indeed, when it comes to gaps in complement-of-P positions, we do not have to look far afield to find cases where: (i) movement, base-generated empty categories, and radically missing structure have all been entertained; (ii) the gaps "alternate" with overt "pronominals"; and (iii) the versions with gaps diverge in subtle and mysterious ways from the versions with overt pronominals.

${ }^{15}$ G\&S make the parasitic gap argument based on examples like (i):

(i) *John filed the papers $s_{\mathrm{i}}$ with doodles on _i [without having read $p g_{\mathrm{i}}$ ].

However, (i) does not seem relevant, since an accepted case of A-bar movement, e.g. relative clause formation, across a similar span does not license a parasitic gap.

(ii) *John [filed [the papers ${ }_{i}$ that the law specified_i] [without having read $p g_{i}$ ].

${ }^{16}$ G\&S note in addition that movement of the Ground to subject position would incorrectly predict (52a and b) to be bad, as Improper Movement and Weak Crossover violations, respectively. 
5.2. GERMAN(IC) R-PRONOUns. ${ }^{17}$ (van Riemsdijk 1978, Koopman 2010, Abels 2012, i.a.) In German, weak neuter pronoun es ('it') cannot be the complement of spatial (or most other) Ps; instead, one finds (some variant of) $d a(r)$-, known as an R-pronoun, obligatorily procliticized to (an allomorph of) the preposition:

Fritz hat gestern $\{$ daran /*an es\} gedacht.

Fritz has yesterday $\{$ DAR-on/*on it $\}$ thought

'Fritz thought about it [lit. thereon] yesterday.'

With other $3^{\text {rd }}$ person pronouns, $d a(r)$ - forms alternate with canonical $\mathrm{P}$-pronoun orders if the referent is inanimate, but are excluded if the referent is human, or animal viewed humanistically (Müller 2000) (recall the possible exclusion of human/animate OLP Grounds from §2.2):

$$
\begin{aligned}
& \text { Maria mußte noch oft daran denken. vs. ... an sie denken. } \\
& \mathrm{M} \text { had.to still often DAR-on think on 3SG.F think } \\
& \text { 'Maria still had to often think about it/*her.' '...about it/her.' }
\end{aligned}
$$

Intriguingly, there are dialectal patches, especially in northern Germany, where the otherwise obligatory $d a(r)$ morpheme can disappear. ${ }^{18}$ Is it conceivable that BrEng is leveraging the same machinery (whatever it might be)? Fleischer (2002) notes optionality of $d a(r)$ - in (68); the two examples are drawn from the same page of a dialectal German source.

(68) North Saxon (Fleischer 2002:377)

a. Ja, aver Hinnerk, man dröögt sik doch de Han'n nich drin af! ja aber Hinnerk man trocknet sich doch die Hände nicht DAR-in ab yes but $\mathrm{H} \quad$ one dries self yet the hands not therein off 'Well, Hinnerk, but one does not dry off one's hands in it!'

b. Dat hangt anne Wand un lett witt, un mandröögt sik de Han'n in af. das hängt an=der Wand und sieht-aus weiß und man trocknet sich die Hände in ab that hangs on=the wall and looks white and one dries self the hands in off 'It hangs on the wall and looks white, and one dries off one's hands in it.'

In some dialects (not regionally restricted), there is a particular preposition (often mit) with which $d a(r)$ - is mostly or entirely dropped, though $d a(r)$ - is required with other prepositions.

(69) Colmarien (Alsatian) (Fleischer 2002:334)

$\ddot{i}$ nimm $d$ ' rüet un schlâ-di mit

ich nehme die Rute und schlage dich mit

I take the rod and hit you with

'I take the rod and hit you with it.'

But the most common dialectal situation, according to Fleischer, is that a number of prepositions allow omission of $d a(r)$-. When $d a(r)$ - does surface it is almost always displaced leftward from the preposition (not allowed in the standard language), often appearing sentence-initially (70) but occasionally elsewhere (71). ${ }^{19}$

\footnotetext{
${ }^{17}$ McIntyre (2006:202 \& fn12) independently hints at the potential connection between OLPs and R-pronouns. G\&S (2015a:71f.) observe the parallel restriction to non-human Grounds, but resist trying to unite the phenomena.

${ }^{18}$ A passage cited from the first edition of the Duden (Grebe 1959) by Fleischer (2002:293) suggests the phenomenon was at one time quite common.

${ }^{19}$ Fleischer (2002:408) points out that if, as in (70), $d a(r)$ - can be fronted to first position, then Topic Drop could explain its disappearance from that position (in a V2 clause). But there remain examples, e.g., (68b), that exclude
} 
(70) North Saxon (Fleischer 2002:408) (Dar) kaamt se veel billiger bi weg. da kommen sie viel billiger bei weg DAR come.3PL they much cheaper by away 'They come away much cheaper (there)by.'

(71) East Pomeranian (Fleischer 2002:148)

Se sünd doa sehr besorgt üm.

sie sind da sehr besorgt um they are DAR very worried about

'They are very worried about it.'

[StdGer]

The use of R-pronouns in the standard language is also subject to semantic restrictions based on the nature of the spatial relation, e.g. (72), modeled on (28d), in turn inspired by (77) below.

(72) Ein Flugzeug war am Himmel, und ein Vogel war auch \{am Himmel/*dran\}. an airplane was at.the sky and a bird was also \{at.the sky /*DAR-at\}

5.3. FRENCH "ORPHAN PREPOSITIONS." Three facts about a superficially similar phenomenon in French are of interest (Zribi-Hertz 1984, Rooryck 1996, Authier 2016, i.a.). French has two candidates for counterparts to (pieces of?) R-pronouns: de and là (see Noonan (2009) for a detailed attempt to unify French and German) (73). The first point is that these "pronouns" are excluded if the referent is human, as in Germanic (74). The second is that these morphemes do not always surface, suggesting they can be silent (75). The third is that not all spatial relations expressible as e.g. dans $+D P$ are compatible with dedans paraphrases (cf. restrictions on OLP in $\$ 2.4 .2$ and German in §5.2): (76) versus (77a) seems to hinge on containment and/or the difference between material and spatial Grounds (Vandeloise 2017) (cf. (28d)).

(73) Je l'ai mis \{sur l'armoire / dessus/ là-dessus\}.

I it $=$ have put on the $=$ cabinet $/ \mathrm{DE}-\mathrm{on} /$ there $=\mathrm{DE}-\mathrm{on}$

'I have put it $\{$ on the cabinet/on it/on there\}.'

(74) Il y a une mouche \{sur Pierre/ sur lui /* (là-)dessus\}.

it there has a fly $\quad$ on P $\quad /$ on him $/ *$ (there=)DE-on

'There is a fly on Pierre/him.'

(75) a. Le livre est \{là-(*de)derrière /là-dessus /*là-sur\}. the book is $\left\{\right.$ there $=\left({ }^{*} \mathrm{DE}-\right)$ behind $/$ there $=\mathrm{DE}-\mathrm{on} / *$ there $\left.=\mathrm{On}\right\}$

b. Ils y peindront (*là-)dessus. they there will.paint $(*$ there $=$ )DE-on

[dialectally restricted]

(76) Cette eau, ily a du chlore dedans.

this water it there has of.the chlorine DE-in

'This water, there is chlorine in (it).'
a. 'Le ciel, des oiseaux volaient dedans. the sky D birds were.flying DE-in ('The sky, birds were flying in (it).')
b. Des oiseaux volaient dans le ciel. D birds were.flying in the sky 'The birds were flying in the sky.'

6. Concluding remarks. In addition to providing arguments against an A-movement analysis, we hope to have sharpened the empirical landscape that an analysis of OLPs should account for: restrictions on the distribution and interpretation of OLPs; dialectal variation within BrEng as to 
which prepositions and senses thereof license OLPs; and the Figure Extraction Restriction.

The cross-linguistic observations in $\S 5$ suggest a program of inquiry for understanding OLPs (as does the history of English: older varieties had R-pronouns too (van Riemsdijk 1978)), but there are immediate challenges: there seems to be nothing resembling the have/with licensing requirement in Germanic or French (or Old English) restricting R-pronouns or their omission, ${ }^{20}$ and in Germanic also no restriction to spatial prepositions. ${ }^{21}$ As for how to characterize the parametric differences (i) between BrEng and Eng lacking OLPs, and (ii) among BrEng varieties with regard to the range of participating prepositions, we take the range of data in $\S 5$ as suggestive that there are (micro)parametric choices in this domain, but the relevant literature contains few attempts to formalize them.

\section{References}

Abels, Klaus. 2012. Phases: An essay on cyclicity in syntax. Berlin: De Gruyter.

Algeo, John. 2006. British or American English? A handbook of word and grammar patterns. Cambridge: Cambridge University Press.

Authier, J.-Marc. 2016. French orphan prepositions revisited. Probus 28. 231-270.

Belvin, Robert Stallings. 1996. Inside events: The non-possessive meanings of possession predicates and the semantic conceptualization of events. Los Angeles: University of Southern California PhD dissertation.

Belvin, Robert \& Marcel den Dikken. 1997. There, happens, to, be, have. Lingua 101. 151-183. Bošković, Željko. 1992. Clausal selection, subjacency, and minimality. Ms., University of Connecticut, Storrs.

Chomsky, Noam. 1977. On Wh-movement. In Peter W. Culicover, Thomas Wasow \& Adrian Akmajian (eds.), Formal syntax, 71-132. New York: Academic Press.

Cinque, Guglielmo \& Luigi Rizzi (eds.). 2010. Mapping spatial PPs: The cartography of syntactic structures, vol. 6. Oxford: Oxford University Press.

Corver, Norbert. 2017. Freezing effects. In Martin Everaert \& Henk C. van Riemsdijk (eds.), The Wiley Blackwell companion to syntax, 2nd edn. Hoboken, NJ: Wiley Blackwell.

Emonds, Joseph. 1994. Two principles of economy. In Guglielmo Cinque, Jan Koster, Jean-Yves Pollock, Luigi Rizzi \& Raffaella Zanuttini (eds.), Paths toward Universal Grammar: Studies in honor of Richard S. Kayne. 155-172. Washington, DC: Georgetown University Press.

Fleischer, Jürg. 2002. Die Syntax von Pronominaladverbien in den Dialekten des Deutschen: eine Untersuchung zu Preposition Stranding und verwandten Phänomenen. Wiesbaden: Franz Steiner.

Grebe, Paul (ed.). 1959. Duden Grammatik der deutschen Gegenwartssprache. Mannheim: Dudenverlag des Bibliographischen Instituts.

Griffiths, James \& Craig Sailor. 2015a. Prepositional object gaps in British English. Linguistics in the Netherlands 2015. 63-74.

Griffiths, James \& Craig Sailor. 2015b. PPs with gaps in. Paper presented at the Annual Meeting of Linguistics Association of Great Britain, London, September.

Griffiths, James \& Craig Sailor. 2017. Probing the PP domain: Complex possessive PPs in British English. Talk presented at Morphosyntactic Variation in Adpositions, Cambridge.

Harley, Heidi. 1998. You're having me on! Aspects of have. In Jacqueline Guéron \& Anne Zri-

\footnotetext{
${ }^{20}$ That said, intriguingly, Fleischer (2002:333) cites one German dialect (spoken in Cattenstedt, Nordharz, Eastphalian) that is described as dropping DAR just in the presence of the verbs have, give and get.

${ }^{21}$ In French, là is locational but de-forms are unrestricted.
} 
bi-Hertz (eds.), La grammaire de la possession. 195-226. Nanterre: Université Paris X. Harves, Stephanie \& Richard S. Kayne. 2012. Having 'need' and needing 'have'. Linguistic Inquiry 43. 120-132. https://doi.org/10.1162/LING_a_00076.

Kimball, John P. 1973. Get. In John Kimball (ed.), Syntax and Semantics, vol. 2, 205-215. New York: Seminar Press.

Koopman, Hilda. 2010. Prepositions, postpositions, circumpositions, and particles: The structure of Dutch PPs. In Cinque \& Rizzi. 26-73.

Levinson, Lisa. 2011. Possessive with in Germanic: Have and the role of P. Syntax 14. 355-393. McIntyre, Andrew. 2005. Preliminary conjectures on inversion and decomposition analyses for have, with and double objects. Ms., Leipzig University.

McIntyre, Andrew. 2006. The interpretation of German datives and English have. In Daniel Hole, André Meinunger \& Werner Abraham (eds.), Datives and other cases: Between argument structure and event structure. 185-211. Amsterdam: John Benjamins.

Müller, Gereon. 2000. Das Pronominaladverb als Reparaturphänomen. Linguistische Berichte 182. 139-178.

Myler, Neil. 2016. Building and interpreting possession sentences. Cambridge: MIT Press.

Noonan, Máire. 2009. A 'clitic' position inside PPs: revenons là-dessus. Paper presented at the $39^{\text {th }}$ Linguistic Symposium on Romance Languages, University of Arizona, Tucson.

Pesetsky, David Michael. 1982. Paths and categories. Cambridge, MA: MIT PhD dissertation.

Quirk, Randolph, Sydney Greenbaum, Geoffrey Leech \& Jan Svartvik. 1985. A comprehensive grammar of the English language. London: Longman.

Riemsdijk, Henk van. 1978. A case study in syntactic markedness. Lisse: Peter de Ridder.

Ritter, Elizabeth \& Sara Thomas Rosen. 1997. The function of have. Lingua 101. 295-321.

Rooryck, Johan. 1996. Prepositions and minimalist Case marking. In Höskuldur Thráinsson, Samuel David Epstein \& Steve Peter (eds.), Studies in comparative Germanic syntax, vol. 2, 226-256. Dordrecht: Kluwer.

Sailor, Craig \& James Griffiths. 2017. PPs with gaps in. Talk given at the Linguistic Society of America Annual Meeting, Austin, Texas, January.

Schütze, Carson T. 2001. Semantically empty lexical heads as last resorts. In Norbert Corver \& Henk van Riemsdijk (eds.), Semi-lexical categories: On the content of function words and the function of content words. 127-187. Berlin: Mouton de Gruyter.

Stowell, Tim \& Diane Massam. 2017. Introducing register variation and syntactic theory. [Introduction to special issue.] Linguistic Variation 17(2). 149-156.

Svenonius, Peter. 2010. Projections of P. In Cinque \& Rizzi, 127-160.

Swan, Michael. 1995. Practical English usage, 2nd edn. Oxford: Oxford University Press.

Tremblay, Mireille. 1996. Empty prepositions and UG. In José Camacho, Lina Choueiri \& Maki Watanabe (eds.), Proceedings of the Fourteenth West Coast Conference on Formal Linguistics. 557-570. Stanford: CSLI.

Vandeloise, Claude. 2017. Three basic prepositions in French and English: A comparison. Corela [online], HS-23. https://doi.org/10.4000/corela.5033.

Wexler, Kenneth \& Peter W. Culicover. 1980. Formal principles of language acquisition. Cambridge: MIT Press.

Zribi-Hertz, Anne. 1984. Orphan prepositions in French and the concept of null pronoun. Recherches linguistiques 12. 46-91. 